\title{
O impacto da educação a distância na identidade docente
}

\author{
El impacto de la educación a distancia en la identidad docente \\ The impact of distance education on the teaching identity
}

Bárbara Regina Gonçalves $\operatorname{Vaz}^{1}$

\begin{abstract}
Resumo
O discurso recorrente e que vem se acentuando sobre a necessidade de uma educação de qualidade e continuada, ocasionada pelas tantas demandas da globalização, vem desafiar os sistemas educacionais. Nesse cenário é que a EAD, conquista seu espaço na sociedade, abrangendo um número crescente de sujeitos. As estratégias propostas pelo BM privilegiam a formação rápida e barata como critérios de eficiência, percebendo-se uma reestruturação capitalista na qual a educação está inserida em uma realidade econômica que busca adequar-se ao mercado. Daí, a emergência de outras modalidades de ensino, como a EAD que tem se destacado nos discursos educacionais e vêm causando grande impacto na (re)configuração da identidade profissional docente. Nessa perspectiva propõese analisar e problematizar as mudanças causadas no processo de (re)configuração da identidade do profissional docente na modalidade à Distância, em um estudo de caso no curso de licenciatura em Matemática EAD da UFPEL, através de análise documental, bibliográfica e de discurso dos professores e coordenadores. Este artigo é parte constituinte de uma pesquisa qualitativa que culminou em minha tese de doutorado, a fim de, analisar, compreender e interpretar como a EAD corrobora na (re)configuração da identidade do professorado. As mudanças no mundo do trabalho alcançaram o âmbito escolar, exigindo do professorado um novo perfil, com o acréscimo de suas atribuições, desencadeando um processo de precarização do trabalho.
\end{abstract}

Palavras-Chave: educação; identidade docente; modalidade a distância; processo de trabalho docente; reconfiguração;

\section{Resumen}

El discurso recurrente y que viene acentuando sobre la necesidad de una educación de calidad y continuada, ocasionada por las tantas demandas de la globalización, viene a desafiar los sistemas educativos. En ese escenario es que la EAD, conquista su espacio en la sociedad, abarcando un número creciente de sujetos. Las estrategias propuestas por el BM privilegian la formación rápida y barata como criterios de eficiencia, percibiendo una reestructuración capitalista en la cual la educación está inserta en una realidad económica que busca adecuarse al mercado. De ahí, la emergencia de otras modalidades de enseñanza, como la EAD que se ha destacado en los discursos educativos y vienen causando gran impacto en la (re) configuración de la identidad profesional docente. En esta perspectiva se propone analizar y problematizar los cambios causados en el proceso de (re) configuración de la identidad del profesional docente en la modalidad a Distancia, en un estudio de caso en el curso de licenciatura en Matemáticas EAD de la UFPEL, a través de análisis documental, bibliográfico y bibliográfico de discurso de los profesores y coordinadores. Este artículo es parte constituyente de una investigación cualitativa que culminó en mi tesis de doctorado, a fin de analizar, comprender e interpretar cómo la EAD corrobora en la (re) configuración de la identidad del profesorado. Los cambios en el mundo del trabajo alcanzaron el ámbito escolar, exigiendo del profesorado un nuevo perfil, con el acrecimiento de sus atribuciones, desencadenando un proceso de precarización del trabajo.

Palabras claves: la educación; identidad docente; modalidad a distancia; proceso de trabajo docente; reconfiguración;

\begin{abstract}
The recurrent discourse that has been accentuated on the need for a quality and continuous education, caused by the many demands of globalization, comes to challenge the educational systems. In this scenario, the EAD

\footnotetext{
${ }^{1}$ Doutora em Educação; Universidade Federal do Pampa - UNIPAMPA; Jaguarão, RS, Brasil; bgvduarte@gmail.com
} 
conquers its space in society, covering a growing number of subjects. The strategies proposed by the BM favor rapid and inexpensive training as criteria of efficiency, perceiving a capitalist restructuring in which education is embedded in an economic reality that seeks to adapt to the market. Hence, the emergence of other teaching modalities, such as ODL that have been prominent in educational discourses and have had a great impact on the (re) configuration of the professional teacher identity. In this perspective it is proposed to analyze and problematize the changes caused in the process of (re) configuring the identity of the teaching professional in the Distance modality, in a case study in the undergraduate course in Mathematics EAD of UFPEL, through documentary, bibliographic and of teachers and coordinators. This article is part of a qualitative research that culminated in my doctoral thesis, in order to analyze, understand and interpret how EAD corroborates the (re) configuration of the teacher's identity. The changes in the world of work reached the school level, requiring a new profile of the teaching staff, with the addition of their attributions, triggering a process of precariousness of work.

Keywords: education; teacher identity; distance modality; teaching work process; reconfiguration;

\section{Introdução}

É possível identificar uma expressiva alteração na organização do processo de trabalho docente ao se analisar as políticas públicas que permeiam o âmbito educacional desde o início dos anos 90. As grandes e significativas transformações no contexto da globalização, que afetaram e afetam diferentes dimensões da sociedade estão ocorrendo em todos os setores do conhecimento. A educação é igualmente atingida por esse processo.

Atualmente, é fato que o discurso corrente e que vem se acentuando sobre a necessidade de uma educação de qualidade e continuada, ocasionada pelas tantas demandas da globalização, vem desafiar os sistemas educacionais existentes. Nesse cenário é que a educação à distância (EAD) vem conquistando, a cada dia mais, o seu espaço na sociedade, abrangendo um número crescente de sujeitos e galgando, em vários setores sociais, o reconhecimento como uma modalidade de educação apropriada para a concretização de metas de políticas públicas educacionais, por ser apontada como um dos caminhos para a democratização da educação, em especial, nos países como o Brasil, onde há grande dispersão geográfica dos alunos.

Um dos fatores que mais evidencia como principal motivo para o amplo processo de expansão da EAD é o aumento do emprego das tecnologias de informação e comunicação (TIC), em todos os campos da sociedade, perpetrando mudanças no ritmo e estilo de vida das pessoas, nos mais diversos âmbitos. Isto decorre no sistema educacional, marcado pela falta de oferta de determinados cursos em algumas regiões, principalmente nas instituições públicas e privadas de Ensino Superior. Além disso, é inegável que esta modalidade de ensino vem se configurando à medida que proporciona maior flexibilidade e rompe com a barreira de tempo e espaço.

Essa modalidade de ensino passa a ser pela primeira vez contemplada formalmente através da LDB - Lei $n^{\circ}$ 9.394/96 no título VIII, artigo 80, determinando que: “O Poder Público 
incentivará o desenvolvimento e a veiculação de programas de ensino a distância, em todos os níveis e modalidades de ensino, e de educação continuada." (BRASIL - LDBEN, 1996). Anteriormente a esta lei, a EAD foi apresentada no planejamento de políticas públicas, ao elaborarem o Plano Decenal de Educação para Todos (1993 - 2003), o qual sofreu grande influência por parte da Conferência de Educação para Todos (1990), realizada em Jomtien, na Tailândia, convocada por organismos internacionais como, a Organização das Nações Unidas para a Educação, a Ciência e a Cultura (UNESCO); o Fundo das Nações Unidas para a Infância (UNICEF); o Programa das Nações Unidas para o Desenvolvimento (PNUD) e o Banco Mundial, na qual o Brasil esteve entre os 155 participantes. As disposições tomadas nesta conferência foram resumidas na Declaração Mundial de Educação para Todos, a qual deveria estabelecer as bases dos planos decenais de educação aos países que assinaram tal documento, objetivando a universalização da educação básica.

Com o intuito de apoiar os esforços nacionais para implementar os planos de educação básica, a Declaração Mundial de Educação para Todos define muitas atividades que poderiam ser realizadas conjuntamente pelos países. Tais atividades deveriam ser idealizadas visando as vantagens comparativas dos países participantes e um aproveitamento das economias de escala. De tal modo, a gestão e a utilização dos serviços de EAD foi entendida como área adequada a esse meio de colaboração regional (NOGUEIRA, 2011)

A partir daí é possível compreender a influência de organismos internacionais desde o início da institucionalização da EAD no Brasil, a qual vem recebendo cada vez mais atenção por parte das políticas públicas, em especial no ensino superior. A forma como vem sendo implementada no Brasil, particularmente nas instituições privadas, decorre de orientações que podem ser encontradas nas políticas do Banco Mundial. As estratégias propostas por este organismo internacional contemplam a redução de custos, a cobrança de taxas para os níveis mais altos de ensino, a avaliação externa, a descentralização administrativa, o aumento de treinamentos para os professores e o acréscimo na formação stricto sensu, privilegiando a formação rápida e barata como critério de eficiência (ANDRIOLI, 2002). Percebe-se uma reestruturação capitalista na qual o âmbito escolar está inserido em uma realidade econômica que busca adequar-se ao mercado.

Daí, a emergência de novas modalidades de ensino, como a educação a distância que tem se destacado nos discursos educacionais e vêm causando grande impacto na organização de currículos, no processo de trabalho docente e na reconfiguração da identidade profissional desses docentes. 
No cenário das políticas de EAD, há diferentes formas e estruturas de cursos sendo implementados. No que diz respeito a oferta desta modalidade nas instituições federais, a EAD está organizada de maneira bastante específica, gerando impactos muito significativos para o que concerne ao trabalha docente. Isto nos leva a estabelecer a hipótese de que existem mudanças extremamente significativas na identidade docente em função das alterações produzidas no processo de trabalho docente oriundas da EAD.

Esse artigo tem como objeto a reconfiguração da identidade docente decorrente do processo de trabalho na educação a distância. Tendo por objetivo principal analisar e problematizar a reconfiguração da identidade docente a partir de um estudo de caso no Curso de Licenciatura em Matemática a Distância da Universidade Federal de Pelotas, através do programa Universidade Aberta do Brasil.

\section{A reconfiguração da identidade docente a partir das novas relações entre os diferentes sujeitos do processo de trabalho na educação a distância}

O Curso de Licenciatura em Matemática a Distância (CLMD) foi aprovado pelo Conselho Universitário da UFPEL através da Resolução no 1 de 28 de abril de 2004. Tal curso foi responsável por levar ao credenciamento da Instituição junto ao Ministério da Educação para oferecer cursos a Distância, iniciando suas atividades com o Programa Pró-Licenciatura e posteriormente aderindo a Universidade Aberta do Brasil.

Segundo consta no Projeto Pedagógico do Curso (PPC), em sua constituição original os professores atuantes eram oriundos do ensino presencial, dividindo, inclusive, sua carga de trabalho com atividades de ensino nas duas modalidades. Isso fez com que ambas as modalidades fossem tratadas como tendo as mesmas necessidades sem perceber suas especificidades. Com isso, o currículo do Curso de Licenciatura em Matemática a Distância manteve o caráter fragmentado por disciplina, a imposição de pré-requisitos curriculares e a sequência de saberes pré-estabelecidos.

Esse cenário se modifica a partir de 2010, com o ingresso de docentes para o trabalho exclusivo com o Curso, quando uma nova identidade pautada na diferenciação das modalidades e das funções dos sujeitos envolvidos começa a ser sugerida. Essa identidade se constitui a partir da reestruturação do Projeto Político Pedagógico do Curso, organizando um currículo não sequencial, por eixos temáticos e produzido para a formação inicial de um professor de matemática.

$\mathrm{Na}$ apresentação do curso que consta no PPC indica que seu público-alvo são indivíduos com o Ensino Médio completo e aprovados no processo de seleção elaborado para 
o Curso; com número de vagas definido pelo Colegiado do Curso, de acordo com a demanda dos Polos de Apoio Presencial e financiamento específico; tendo regime semestral, com duração formal mínima de quatro anos, com o desdobramento em oito semestres, sendo que cada semestre será executado em média em 17 semanas.

O Curso tem por objetivo geral formar professores de Matemática para atuarem nos anos finais do Ensino Fundamental e no Ensino Médio, habilitando-os para realizar intervenções nos processos de ensino-aprendizagem de Matemática, atuando para a formação integral do aluno como cidadão crítico, reflexivo e atuante, contribuindo para a qualidade de ensino nas escolas e sendo um agente integrador na relação comunidade-escola. Preparado ainda para continuidade de estudos em nível de Pós-Graduação em Educação, em Educação Matemática ou em áreas afins.

Apesar do curso ser desenvolvido praticamente todo a distância, são oferecidas atividades presenciais semanais não obrigatórias para os estudantes de cada Pólo, no intuído de promover uma aprendizagem colaborativa e participativa. Além destas, em conformidade com a lei, as avaliações serão presenciais, constituindo atividades obrigatórias.

Entendendo que um professor se constitui a partir de sua prática, o curso conta ainda com estágios obrigatórios, no intuito de preparar o aluno para o exercício da docência, compreendendo as etapas necessárias para concluir sua formação.

A comunicação estabelecida entre professores e alunos se dá basicamente de forma virtual através da Plataforma Moodle, onde é possível realizar atividades, armazenagem de material didático, comunicação on line via Chat, entre outros, e também em encontros presenciais.

Para acompanhar o desenvolvimento do aluno será estabelecida uma rotina de observação, descrição e análise contínua da produção desse aluno, devendo ser realizada através de orientação acadêmica, a qual ficará a cargo dos tutores e professores responsáveis pela execução de disciplinas do curso. Caso seu rendimento não seja satisfatório, será sugerido ao aluno refazer seu percurso.

Entendendo a avaliação como um processo contínuo, será realizado no início do Eixo uma avaliação com o intuito de verificar quais concepções o aluno tem sobre o conteúdo matemático específico. No decorrer serão aplicadas mais duas avaliações presenciais, sendo, preferencialmente, uma prova e a apresentação de um Seminário, o que corresponderá a 60\% do total da nota do aluno, ficando os outros $40 \%$ restantes destinados a avaliações online realizadas no ambiente virtual de aprendizagem. 
A materialização das relações entre os diferentes sujeitos protagonistas do processo de trabalho na UAB indica um reposicionamento docente, caracterizando a constituição de uma nova identidade docente, diversa daquela estabelecida na educação presencial. A partir da descrição dos cargos, conforme apresentado na seção anterior, os diferentes sujeitos passam a se relacionar gerando um processo de trabalho específico para a UAB, mas, sobretudo, característico da EaD. Mais que descrever a seguir o processo de trabalho, pretendo mostrar o aparecimento de novas relações e, com elas, uma nova identidade docente.

Por falar em processo de trabalho docente no CLMD, acho importante discutir um pouco sobre a contratação de professores pesquisadores e como está estruturada a hierarquia desse curso na modalidade a distância na UFPel.

É pertinente lembrar que o CLMD era formado inicialmente por oito professores efetivos, quando ainda existia o CEAD. Desses oito professores, sete professores são concursados exclusivamente para EAD e um professor concursado do IFM que foi transferido para o CEAD, ou seja, todos esses oito professores tinham exclusividade no CLMD/EAD/UFPel.

Quando o CEAD foi extinto e o CLMD migrou para o IFM, deixou de existir essa exclusividade. Porém, em reunião junto ao Departamento, foi permitido exclusivamente ao professor que ocupa a função de coordenação do CLMD, cumprir sua carga horária unicamente no curso. Caso o professor opte por deixar a coordenação, terá obrigatoriedade de cumprir 12 horas aula na modalidade presencial, embora seja possível acumular uma remuneração através de uma bolsa e continuar ministrando suas aulas também na modalidade a distância.

Essa conquista só se tornou possível devido à enorme demanda que a função administrativa de coordenação exige. Com todos esses encargos seria impossível cumprir carga horária presencial devido sua rigidez de turnos e horários. Dessa forma, o professor não deixa de cumprir seus encargos pedagógicos no CLMD devido a flexibilidade da EAD.

Conforme informação prestada pela Coordenadora do curso, quando é necessário chamar um professor para o CLMD, geralmente se coloca um aviso no IFM, solicitando um um docente para atuar na condição de Professor Pesquisador para ministrar determinado componente curricular ou mesmo um conteúdo específico no curso. A prioridade é dada a quem já trabalhou no curso, mas conforme a coordenação,

Se a gente não conseguir e outro professor se candidatar, não posso proibir. Até porque, teoricamente, todo professor com formação em matemática está apto a dar 
aula de qualquer conteúdo da área, embora se sabe que cada professor tem afinidade com um determinado conteúdo. (Coordenadora do curso)

A idéia inicial é solicitar um professor que pertença ao departamento. Caso não haja interesse de nenhum professor ou não tenha nenhum professor com disponibilidade, se realiza uma busca em outros departamentos dentro da instituição - UFPel e que estejam aptos para ministrar tal conteúdo. Caso ainda não seja possível encontrar esse profissional dentro da UFPel, então é aberto um edital externo para professores que atuem em outras instituições. Como enfatizou a Coordenadora do Curso, "hoje até se tem professores pesquisadores sem nenhum vínculo com a UFPel. Tem um da Unipampa de Bagé, tem outro da Furg [...] todos remunerados através de bolsa" (Coordenadora do curso).

Para os componentes curriculares de Libras, Física, e os da área da Educação, não há necessidade de um professor sempre disponível, pois não são contínuos. Nesses casos os professores são chamados conforme a necessidade do eixo e obedecem os mesmos critérios de seleção dos demais.

Para melhor compreensão sobre conteúdos, eixos, componentes curriculares e áreas mencionadas acima, se faz necessário explicar como se dá a organização e arquitetura curricular do curso, a qual divide-se em oito eixos temáticos pautados em quatro conhecimentos para formação do professor de matemática. Esses conhecimentos integram a parte obrigatória do currículo e são os seguintes: 1) Conhecimento do Conteúdo Matemático para Atuação Profissional - Educação básica escolar; 2) Conhecimento do Conteúdo Matemático Especializado - Ensino superior; 3) Conhecimento dos Processos de EnsinoAprendizagem dos Conteúdos Matemáticos - relações pedagógicas, psicológicas, sócio históricas; e 4) Conhecimento do Conteúdo Especializado de Áreas afins para Atuação profissional do Professor de Matemática - outras áreas que colaboram para o ensino da matemática, Língua Brasileira de Sinais, Organização e Políticas Públicas da Educação Brasileira e Física.

Os componentes curriculares que correspondem aos conhecimentos do conteúdo matemático específico (educação básica e ensino superior) são ministrados pelos professores pesquisadores efetivos da área da matemática, vinculados ao IFM. Os demais componentes que correspondem aos conhecimentos dos processos de ensino-aprendizagem e áreas afins, podem ser ministrados pelos professores pesquisadores dos cursos de Engenharia, Arquitetura, Letras, e demais colaboradores.

Cada eixo corresponde a vinte créditos, com cinco componentes curriculares de quatro créditos cada. $\mathrm{O}$ eixo é formado por uma equipe composta por um professor responsável pelo 
eixo, por um professor responsável por organizar as Web conferências, um professor responsável pelas viagens para os polos e aulas presenciais, um professor responsável pelo material didático, um tutor a distância e um tutor presencial.

Cada professor ou cada dupla de professores, que pode ser formada pelo professor responsável pelo eixo e o professor responsável pelo material didático, criam os conteúdos definindo quais prioridades e qual enfoque que este terá, além do calendário, planos, ementas, atividades e avaliações. Depois de estruturado, o conteúdo é apresentado para o grupo no intuito de arrumar os detalhes, ajustar a linguagem, fazendo com que o material assuma as características de uma padronização, dessa forma, evita-se que os alunos percebam eventuais trocas de professores de um conteúdo para outro. Essa forma de organização é perceptível nas falas dos professores,

\begin{abstract}
Os efetivos eram muito ligados na organização do material e no planejamento de como o semestre ia ocorrer, então quando eu falo assim: planejamento de material significa desde o calendário, por exemplo, na primeira semana vai trabalhar tais conceitos, na segunda semana vão trabalhar tais e tais conceitos e as atividades vão ser essas, na terceira semana [...] a fórmula tem que ter tais elementos, a resposta pra isso tem que ser aquela, o tutor tem que fazer tal intervenção, então era toda essa minucia do trabalho $(\mathrm{P} 2)$
\end{abstract}

Na gestão anterior tinha um grupo para a correção, o outro das atividades, hoje não, tem uma equipe que acompanha um pólo, sendo possível conhecer cada aluno, seus problemas, características, enfim, todo histórico do aluno. (P1)

O curso possui duas grandes equipes de tutores, uma equipe que só realiza a gravação de vídeo aulas com os conteúdos e exercícios orientados pelos professores, e outra equipe de orientação e correção das avaliações, e que também cuida dos fóruns e e-mails.

Essas equipes, embora compostas por tutores com no mínimo bacharelado ${ }^{2}$ em matemática, passam por uma capacitação inicial durante dois meses antes do início do semestre, para relembrar o conteúdo específico da área da matemática, e ainda como orientar os alunos, como responder nos fóruns, de forma que o tutor tenha mais domínio sobre o processo de ensino-aprendizagem, demonstrando maior firmeza na hora de responder ao aluno. Segundo a fala da P1 "o grupo tem que ter coesão, professores e tutores".

Durante o período que a pesquisa foi realizada no curso, o processo de organização e orientação do eixo se dava, primeiramente, através de uma reunião com toda equipe responsável pelo eixo, realizada semanalmente nas quintas, a partir das $14 \mathrm{~h}$, onde eram definidas as atividades para semana seguinte. Essa reunião se estendia até umas $17 \mathrm{~h}$. Por volta

\footnotetext{
${ }^{2} \mathrm{~A}$ preferência é dada para quem tem Licenciatura.
} 
desse mesmo horário chegavam os tutores para capacitação que durava em média $1 \mathrm{~h}$, até umas $18 \mathrm{~h}$. Posteriormente, todos se dirigiam a reunião administrativa com a coordenadora do curso e/ou a coordenadora de tutoria e a coordenadora do eixo, onde eram repassadas as orientações referentes as atividades da semana. Na fala abaixo se apresenta um exemplo de como são repassadas as orientações para os tutores,

Essa reunião serve pra passar coisas do tipo ... pessoal, na próxima semana terá prova, depois que a prova chegar, vocês terão 10 dias pra correção e postagem das notas. Na próxima semana tem que gravar tais vídeos ... dependendo do recado ia pra cada equipe responsável, ou equipe de avaliação e correção ou equipe de gravação (P1)

Segundo a fala da coordenadora do curso, a cada semestre vai "se aparando as arestas" na tentativa de ajustar as atividades e funções que cada um exerce no curso, seja ele um professor pesquisador, um tutor a distância, um tutor presencial, ou até mesmo um coordenador.

Como exemplo desse processo de reconstrução constante do curso, a coordenadora coloca que nesse semestre, referindo-se a 2014/2, os tutores presenciais passaram a ter atribuições bem pontuais, como forma de incentivo e reconhecimento de seu trabalho. Ainda segundo a coordenadora, os tutores presenciais não se sentiam úteis e muito menos se sentiam parte da equipe de professores do CLMD da UFPEL. A partir daí começou a ser repensado no curso como se enxerga o papel do tutor, que passa a ser reconhecido como parceiro da equipe de trabalho. Tal reconhecimento, acarretou na melhoria do tempo de retorno das dúvidas dos tutores. Coisa que era demorado e acabava por causar desânimo nos tutores, passou a ter prazo estabelecido de no máximo uma semana para o professor pesquisador responder ao tutor. Sobre as novas percepções no processo de trabalho na EAD, a Coordenadora do curso coloca, "eu primo muito pelo coletivo de trabalho. O professor tem que ter respeitado sua liberdade, mas também acho que na EAD tem que ter uma normatização para que o coletivo seja organizado e padronizado, o que é importantíssimo na $\mathrm{EaD}$ (Coordenadora do curso).

Têm tutores que se veem como professores, até porque possuem a mesma qualificação ou mais do que alguns professores, mas tem outros tutores que não se reconhecem assim, acham que fazem somente o operacional, uma vez que muita coisa vem pronta para o tutor, “[...] onde não existe um planejamento de aula não existe professor, eu não me enxergo professor" (T4). No caso do cargo de professor pesquisador, como o próprio nome já fala, este não sofre menosprezo, pois seu cargo já é de professor. Porém, o cargo de tutor que remete somente a cuidar, acaba sendo menosprezado, inferiorizado. 
Outra reestruturação do curso foi referente a obrigatoriedade dos encontros presenciais no pólo, definindo-se 10 encontros obrigatórios, o que anteriormente não havia. O grupo de alunos só se encontrava em dia de prova o que dificultava pensar no coletivo, que eles faziam parte de uma turma. Essa dificuldade para se encontrarem era uma das causas de impossibilita-los de fazer exercícios de forma coletiva, de fazerem atividades em grupo, e até de terem um sentimento de pertencimento a uma turma, o que se diferencia do presencial. Com o retorno da obrigatoriedade dos encontros presenciais no polo, além de facilitar para executar o planejamento de uma turma, valoriza o tutor presencial que deixa de se enxergar como aquela pessoa que só abria a porta da sala do pólo e passa a se reconhecer como parte da equipe de trabalho, com funções específicas como apresentar frequência dos alunos (isso inclui lançar no sistema os atestados médicos e de trabalho, bem como enviar pelo correio os originais para a Sede do curso), enviar dúvidas, fazer uma interação com os professores do eixo, relatar eventuais problemas e solicitar visitas ao polo caso haja necessidade. A fala abaixo evidencia o que foi exposto acima,

é muito fácil a gente planejar, mas outra coisa é executar o que foi planejado, pois cada pólo tem suas especificidades, suas características de alunos e as vezes isso dificulta a execução de um planejamento inteiro [...] além disso, a figura do tutor se torna imprescindível na interação entre os alunos e os PP's. (P3)

No que diz respeito às diferenças entre as atribuições dos professores pesquisadores e os tutores, uma das dúvidas mais frequentes se refere a quem tem a responsabilidade de atender e acompanhar os alunos. Os professores pesquisadores não estabelecem contato com os alunos, somente com os tutores, e estes por sua vez realizam o acompanhamento dos alunos. Os únicos professores que eventualmente podem estabelecer algum contato com os alunos, como responder algum Email, são os coordenadores de eixo. Os PP's são responsáveis por produzir videoaulas, realizar webconferencias somente para revisão, montar material escrito, além de ficarem encarregados pela postagem do material no Moodle. Já os tutores são responsáveis pela interação direta com os alunos, acompanhando-os e orientando-os durante todo o período do curso, o que inclui acompanhar os fóruns, dar retorno às dúvidas dos alunos, auxiliar na resolução das atividades e na correção das avaliações.

Existe ainda a equipe de estágios, que é uma equipe separada da equipe dos professores dos eixos. O estágio é um eixo a parte, onde consta a coordenadora de estágios que gerencia toda equipe, os orientadores de estágio que são cadastrados como professores pesquisadores, porém o nome da sua função é diferenciado. Os orientadores de estágio têm como atribuições orientar artigos, fazer as visitas, realizar a correção do planejamento de aula 
que autoriza as aulas dos alunos. Antes do aluno começar o estágio, ele precisa apresentar todo o planejamento das aulas para o seu orientador e só será liberado para o aluno dar início ao estágio depois que todo seu planejamento for corrigido e autorizado pelo orientador de estágio. Os orientadores geralmente devem ser de Pelotas, cidade sede do curso, caso não se encontre, então se busca na própria cidade do pólo.

Além desses, também completam a equipe de estágios os co-orientadores de estágio e que são cadastrados como tutores presenciais, eles se fazem presentes no pólo e dentre suas atribuições está auxiliar na montagem dos planos de estágio junto com os alunos, também realiza as visitas, efetua a correção dos portfólios quinzenais, e dividem com os coordenadores as atividades de avaliação e todo suporte necessário para que o acadêmico faça com sucesso seu estágio.

Essa equipe se reúne uma vez por semana, em um encontro virtual via webconferencia, entre os orientadores e co-orientadores de estágio, com o objetivo de afinar as avaliações, tentar maior proximidade entre as equipes, colocar os critérios estabelecidos para correção dos planos de aula, orientar como se faz uma visita, orientar o que poderia se considerar um problema grave durante um estágio e se esse é caso de ser encaminhado para o colegiado ou não. Em se tratando de colegiado, no período de realização da pesquisa recentemente havia se formado um novo colegiado o qual ainda não tinha se reunido.

É unânime nas falas das coordenadoras a necessidade de uma equipe estrutural polidocente, para compor o processo de trabalho docente da EAD no CLMD. Essa equipe contaria com um profissional da área da computação que alimentasse a página do curso e resolvesse problemas da área de ti, um profissional de webdesign, um para orientação educacional que corrija o português, outro profissional para cuidar da diagramação de livros e para cuidar da edição de vídeos. Seria uma equipe diversificada que pudesse auxiliar outros tipos de materiais, e que faz muita falta para fazer um curso em EAD funcionar.

Durante as entrevistas, a idéia da valorização dos tutores no curso investigado é retomada inúmeras vezes. Dessa forma, é perceptível que a partir da iniciativa de novos movimentos estabelecidos pela equipe de coordenadores do curso a fim de reorganizar o processo de trabalho juntamente com políticas educacionais que fortalecem a idéia de desvalorização do capital humano, uma nova identidade docente vem se constituindo.

Essa nova identidade que surge na EAD e é perceptível entre os professores do CLMD, é influenciada por dois diferentes tipos de valorização. Enquanto gestão de curso, a valorização dos tutores veio através da inserção deles na equipe além do reconhecimento do seu trabalho como professor do curso, porém, esse reconhecimento desaba no momento em 
que eles recebem uma bolsa no valor de $\mathrm{R} \$ 765,00$ mensais, comprovando o quanto seu trabalho é desvalorizado enquanto política educacional.

O que eu vejo hoje como tutor? Bom, em relação ao trabalho no curso percebo uma evolução por parte da gestão, hoje nos enxergam, não somos mais tão inúteis, invisíveis, uns robozinhos. Hoje não, nosso trabalho é bem aceito como professor. Mas se for pensar na remuneração, a maioria de nós acaba aceitando essa bolsa por desespero, para pagar uma escola pra um filho ou pagar uma faculdade, para somar na renda de professor que já é pouca. Hoje somos uma força de trabalho barata, pois é uma remuneração baixa que não dá direito a vale transporte, a plano de saúde, a nenhum tipo de lei trabalhista e a grande maioria de nós é muito bem qualificado. Da equipe de tutores que trabalha aqui no curso hoje, a maioria tem mestrado e dois inclusive estão fazendo doutorado. (T3)

$\mathrm{Na}$ fala acima percebe-se que mesmo que seja feito o máximo possível para o devido reconhecimento e valorização do lado profissional deles, essa forma de remuneração é vista como "uma piada de muito mau gosto" (T1), e o autor ainda completa "[...] bolsa não tem atestado, bolsa não tem férias, bolsa não tem décimo terceiro e ainda está atrasada desde novembro de 2014" (T1).

Percebe-se uma urgência na legalização da EAD a nível de Brasil pelas instituições. Não falo de um tutor bolsista, mas da função desenvolvida pelo tutor. Se hoje decretassem o término da $\mathrm{UAB}$, principalmente em nível superior de graduação, não vejo como se manteria um curso sem a figura de tutoria. Essas bolsas são uma política de governo que precisa ser revista. É possível perceber a gravidade da situação através da fala da Coordenadora do curso:

\footnotetext{
Pode ser que agora com esse lema da pátria educadora talvez mude alguma coisa, mas se caso isso não mudar acho que temos um futuro meio nebuloso, não sei se bom ou ruim, mas no mínimo nebuloso em relação a tutoria mesmo dos cursos. Hoje se tem uma previsão de greve geral dos tutores, meu laboratório está vazio mas isso não está prejudicando meu curso porque estamos em recesso por 10 dias, mas se o meu semestre começasse na segunda eu estaria em pânico pois não teria como começar um semestre sem tutor
}

Entretanto, não devemos nos ater somente ao contexto das discussões políticas voltadas para EAD, que sem dúvida vem corroborando para a constituição de uma nova identidade docente, mas também devemos analisar sob outro ponto de vista, como esse profissional de EAD, seja professor pesquisador ou tutor se enxerga enquanto profissional e o que mudou na sua prática.

O professor, ao aceitar trabalhar na modalidade a distância, enfrenta uma série de desafios acrescidos dos que já enfrenta no ensino tradicional. Ele arrisca olhar o novo, em uma educação mediada e dependente do uso de Tecnologias da Informação, mas tem como referência e prática a realidade do ensino presencial, em que ele está relativamente à vontade, 
pois ali tem parâmetros e história. Ao serem questionados se viam diferença entre a prática presencial e a prática na EAD e quais seriam essas diferenças, dois sujeitos investigados responderam,

\begin{abstract}
Na EAD é difícil conhecer a situação dos alunos como no presencial pois o ensino é massificado, com muitos alunos em muitos polos ao mesmo tempo. É difícil para o aluno e para o professor que precisa "rebolar" para dar conta do recado. (P2/ grifos do sujeito)

Há diferenças sim. Na prática EAD o professor deve ser bem mais preparado, procurar formas de ensinar [...]. Na prática presencial podemos ver como o aluno reage às atividades e identificamos melhor suas dificuldades e por isso na EAD temos que ser melhor preparados para lidar com quem ensinamos. É uma busca constante por excelência e na maioria das vezes é quase impossível com tantas metas a atingir. (T9)
\end{abstract}

Suas referências foram construídas desde a sua experiência como aluno, depois, nos cursos de formação de professores e, principalmente, na sua prática docente no contexto escolar. É com essa bagagem que ele é desafiado a olhar o novo, demonstrando sua busca pela flexibilização que esse profissional da EAD necessita no seu cotidiano, conforme se analisa na fala do sujeito T4, em resposta à pergunta "Você percebe um certo impacto da EAD no processo de trabalho docente? Se sim, como é que você enxerga esse impacto que a educação a distância vem causando no processo de trabalho docente?"

\begin{abstract}
Então, eu trabalhei com o ensino fundamental e médio (presencial) muitos anos e quando eu me deparei como tutora, eu reproduzia como tutora as aulas de um professor (presencial), mas como professora que teve que planejar aulas a distância eu reparei que existiu uma mudança muito grande no olhar, de como chegar até o aluno, então o que antes pra mim era muito simples se tornou mais complexo no sentindo de ter uma docência compartilhada que eu não tinha, de pensar na educação de outra forma em função da EAD [...] os impactos que eu percebi, eles dizem mais respeito a como enxerga o aluno [...] como enxergar o processo didático [...] o que impactou e continua impactando no meu processo de trabalho docente foi o olhar sobre a docência compartilhada que me diferenciou da professora que eu era antes, dessa possibilidade de comunicação diferente com os alunos e também, na questão do trabalho em equipe. (T4)
\end{abstract}

Na maioria das falas dos professores/tutores, percebe-se que a grande preocupação é com a linguagem que deverá ser utilizada na modalidade a distância e para isso, mais uma vez, surge a figura do tutor, seja presencial ou a distância, como elemento de suma importância na mediação entre professor/aluno. O aluno, apesar de ter passado por muitas transformações ao longo do tempo, continua com algumas necessidades históricas, principalmente no que se refere ao contato de forma presencial com o professor, e este por sua vez, ainda tem a necessidade do contato visual com o aluno, onde é possível perceber a reação 
dele ao conteúdo ministrado. Isso não acontece na modalidade a distância e é por essa razão, que os professores presenciais tem uma enorme dificuldade quando começa a atuar na EAD.

É nesse momento que o professor/tutor percebe a mudança na sua prática, quando ele precisa pensar nas possíveis dúvidas dos alunos e ainda se utilizar de uma linguagem mais aproximada da realidade desses alunos, na montagem do material didático, que se torna quase que uma peça fundamental no processo de ensino/aprendizagem na EAD.

Mesmo o tutor sendo reconhecido como elemento fundamental na EAD, se percebe em suas falas uma disparidade quanto a forma que se veem, quanto a sua identidade dentro da EAD. No questionário foi elaborada uma pergunta somente para os tutores, "Você enquanto tutor na EAD se sente um professor na EAD? Por quê?”. E daí surgiram algumas respostas bem interessantes:

Não sei se sou considerado (pelos colegas), mas me sinto sim, porque os alunos na maioria das vezes estão muito mais presentes ao tutor do que qualquer outro profissional da sede. (T1)

Um pouco, pois de uma forma ou outra acabamos orientando os alunos, porém, percebo uma diferença enorme quanto ao valor das bolsas e nossas atribuições que são bem maiores e principalmente no olhar e postura dos colegas professores. (T4)

O tutor não é um corretor simplesmente, pelo menos aqui, nós temos grupos que buscam a reflexão sobre o trabalho. Especificamente nos estágios nós temos um grupo de formação docente a distância, na área da matemática, que pensa sobre o que está fazendo, então somos todos professores, somos todos professores da universidade, não cabe mais essa diferença ela não se sustenta mais (T2)

Nas respostas dos sujeitos acima percebemos que alguns ainda se sentem menosprezados por parte de alguns colegas professores, mesmo fazendo parte efetivamente do corpo docente, atuando como tal, esses tutores não se sentem reconhecidos pelos colegas, além, é claro, de vir à tona novamente a questão da desvalorização devido a política da mão de obra barata. Essa questão da diferença entre o ser tutor e o ser professor na EAD, também surge em outro momento, ao serem questionados se acreditavam que a EAD corroborava para uma reconfiguração da identidade docente e como eles viam isso,

Penso que sim, ele dá uma forma diferenciada no professor. Conseguimos identificar com clareza a prática e postura dos professores EAD. (T9)

Sim, um professor que trabalha em EAD precisa lidar muito bem com o fator tempo, para estar em sintonia com os alunos. O professor precisa transitar bem em outros campos de conhecimento e trabalhar muito bem em equipe. $(\mathrm{P} 2)$

Mais uma vez percebemos claramente o fator tempo colocado como uma autodisciplina que deve ser adotada pelo profissional da EAD, além é claro de questões como 
a flexibilização, quando o sujeito fala que o "professor deve transitar bem em outros campos de conhecimento e trabalhar muito bem em equipe". Sobre isso, Mill e Fidalgo (2009) colocam que "o trabalho na $\mathrm{EaD}$ é realmente mais exigente e mais cansativo em termos de tempo e atenção do trabalhador" (MILL; FIDALGO, 2009, p. 313).

$\mathrm{Na}$ fala abaixo a questão da flexibilização do professorado aparece novamente como uma forte característica da atuação na educação à distância que tem modificado o processo de trabalho docente, colaborando para uma (re) configuração da identidade docente,

(...) através de trabalho em equipe, docência compartilhada, colaboração em disciplinas, orientação de equipe docente acerca da disciplina, enfim, meu trabalho docente perpassou a sala de aula, tendo uma comunicação mais abrangente, detalhada e compartilhada de meu fazer docente (P3)

Talvez meu olhar já esteja embaçado pela pesquisa e por tantas leituras que venho me debruçando, mas senti na colocação desse sujeito uma certa satisfação ao ter que buscar se flexibilizar como docente. O que se propõe pensar é que o professor, mesmo que parta de um lugar comum e procure fazer na $\mathrm{EaD}$ a mesma e "velha" educação de forma mais performática, com novos recursos, a educação transmissiva e centralizada com o uso de TIC, ele terá que se confrontar com situações inusitadas que provocarão, no mínimo, grande instabilidade. Essa instabilidade torna-se um momento potencial para a reflexão sobre a educação, com a possibilidade de uma ressignificação do papel de docente, propiciando a transformação.

\section{Conclusões}

Nas falas foi possível identificar como os espaços de lazer e descanso, foram tomados ao longo do tempo. Sobre essa "invasão" do espaço privado Mill (2006) aponta as dificuldades que o trabalhador docente enfrenta para administrar seu próprio tempo e espaço de trabalho no contexto familiar e de vida privada, o que torna tempo e espaço de descanso e lazer em horário e local de trabalho. Para Oliveira (2007) o professor confunde os tempos de trabalho e lazer, perdendo a noção temporal e o mesmo acaba trabalhando muito mais em casa com a mediação computador/internet.

Segundo Oliveira (2007) com essas tecnologias, os professores são obrigados a trabalharem mais em um período de tempo que aumentou significativamente nos últimos anos. Deste modo, as tecnologias da informação e da comunicação aumentaram o trabalho dos professores sem que eles tivessem um acréscimo correspondente no tempo para executar 
seu trabalho, causando aumento do ritmo de execução das tarefas e diminuição dos intervalos destinados ao descanso.

Os desafios que emergem da análise do trabalho docente impactado pelas tecnologias nos indicam que, apesar de se apresentarem transvestidos de novos, são velhos conhecidos das lutas sindicais: a forte intensificação do trabalho e a busca incessante de flexibilização das relações de trabalho. A tecnologia, da forma como vem sendo introduzida em nossa sociedade, traz à tona um novo patamar de exploração do trabalho docente que extrapola em muito os limites das jornadas de trabalho estabelecidas nos acordos coletivos.

As novas referências e exigências do que é o próprio trabalho do professor encobre para eles mesmos a visão de que estão sendo superexplorados. A tecnologia aparece muitas vezes nos discursos docentes como um elemento potencializador da sua capacidade de trabalho, tendo em vista que esta permite liberar mais tempo para atividades mais criativas. No entanto, como se pode perceber em várias pesquisas, embora esta variável tenha um fundo de verdade, ela encobre o fato de que o volume de informações que devem ser levadas em consideração pelos professores também aumenta de forma exponencial. Isso implica em maior dedicação de tempo para uma tarefa que na maioria das vezes seria resolvida com a consulta de um ou dois livros.

Percebe-se que boa parte do tempo que os professores dedicação desenvolvimento das atividades didáticas é utilizado em buscas intermináveis nos sites especializados da Internet. Sem contar que muitos ainda têm acesso discado, o que representa um desperdício adicional de tempo com a espera para carregar certos arquivos. Em alguns poucos casos, percebe-se que a atividade cooperativa com outros colegas funciona, no entanto, o mais comum é a manutenção da prática solitária de preparar suas aulas. A intensificação do trabalho docente ocorre de várias formas que não têm sido levadas em consideração na definição das cláusulas contratuais. Percebe-se um aumento de tempo gasto na relação professor-aluno, o que sem as tecnologias ficava restrito ao espaço-tempo da sala de aula. Agora, o espaço se virtualiza, levando os alunos a se corresponderem com os docentes. Afora do previsto formalmente, para esclarecerem dúvidas sobre os conteúdos, fazer sugestões, etc. O espaço abandona a menção em prol de um tempo mais do que sem fronteiras _ professor 24 horas.

Para análise do trabalho dos docentes, certamente, para os tutores há um processo claramente intensificador. Não somente em relação a dimensão da jornada de trabalho, distendida para além dos períodos de dedicação presencial (incluindo até a casa do professor), como também pelo grande número de alunos que cada um precisa dar conta ao longo de uma semana de trabalho. 
A organização dos tempos e espaços da escola, da sala de aula, do professor e dos alunos, para a construção do conhecimento mediado pela tecnologia, não sofrem as alterações e adaptações necessárias à apreensão das novas ferramentas. (FIDALGO e FIDALGO, 2008)

Outrossim, os mecanismos de controle social e de alienação do trabalho docente se fazem presentes de modo cada vez mais sutil e sofisticado. $\mathrm{O}$ aceleramento no ritmo de vida, a busca incessante por produtividade, a necessidade de fazer parte de uma aldeia global torna cada vez mais complexo para o professor gestar as incoerências existentes entre o trabalho que lhe é determinado na contratação e a sua experiência concreta, vivida no dia-a-dia da escola.

O mais complicado é perceber que os docentes acabam desenvolvendo uma visão maniqueísta do uso da tecnologia no trabalho, definindo-a como boa ou ruim, sem contestar aspectos importantes da sua utilização. Contudo, tem-se compreendido uma intenção mais forte de vê-la de maneira domesticada, enaltecendo seus benefícios, mas nem sempre problematizando sobre suas probabilidades de recontextualização e de empregá-la de forma crítica e lúcida na sua experiência de trabalho.

\section{Referências}

ANDRIOLI, A. I. As políticas educacionais no contexto do neoliberalismo. Revista Espaço Acadêmico, Ano 2, $\mathrm{n}^{\mathrm{o}}$ 13, Junho de 2002. Disponível em: http://firgoa.usc.es/drupal/node/6389. Acesso em: Outubro de 2008. (Artigo em Periódico Digital)

BRASIL. Lei de Diretrizes e Bases da Educação Nacional. Lei no 9.394, de 20 de Dezembro de 1996. Disponível em http://portal.mec.gov.br/arquivos/pdf/ldb.pdf. Acesso em: Outubro de 2008 .

FIDALGO, S. R.; FARIA, Lidiane Xavier de; MENDES, Eliandra da Costa. Profissionalização docente e relações de trabalho. Revista Extra-Classe, n.01, v.02, Agosto de 2008. (Artigo em Periódico Físico)

MILL, D. Educação a distância e trabalho docente virtual: sobre tecnologia, espaços, tempos, coletividade e relações sociais de sexo na Idade Mídia. 2006. 322p. Tese (Doutorado em Educação) - Universidade Federal de Minas Gerais, Belo Horizonte, 2006. Disponível em: <http://www.bibliotecadigital.ufmg.br/dspace/handle/1843/HJPB55Y9MT>. Acesso em: Agosto de 2012. (Tese de Doutorado)

MILL, D.; FIDALGO, F. Uso dos tempos e espaços do trabalhador da educação a distância virtual: produção e reprodução no trabalho da Idade Mídia. Cadernos de Educação FaE/PPGE/UFPel, Pelotas, n.32, p.285-318, jan/abr. 2009. (Artigo em Periódico Físico) 
NOGUEIRA, R.; Limites críticos das noções de precariedade e desprecarização do trabalho na Administração Pública, 2011. Rede Observa RH. (Obra completa)

OLIVEIRA, R.P. A transformação da educação em mercadoria no Brasil. Educação \& Sociedade, Campinas, v. 30, n. 108, p. 739-760, out. 2007. (Artigo em Periódico Físico) 